\title{
Anodes - Technology Review
}

\author{
L. Wallis ${ }^{\mathrm{a}}$ and R.G.A. Wills ${ }^{\mathrm{a}}$ \\ ${ }^{a}$ Faculty of Engineering and the Environment, University of Southampton, Highfield, Southampton,
} SO17 1BJ, UK.

\begin{abstract}
Many electrochemical energy storage technologies utilize anodes that are specific to the chemistry of the device. Anodes must be designed for devices including primary and secondary batteries, fuel cells and capacitors. These applications include a diverse range of operational conditions, including aqueous, solid or organic media. This paper will provide a brief overview of anode technologies for medium (e.g. electric and hybrid electric vehicles) and large (e.g. integration of renewable energy generation to electrical networks). Established and developing storage technologies will be discussed to provide an insight into how anodes (materials, manufacturing processes and modes of operation) differ between specific applications and devices. Lead-acid batteries are used as a case study to provide a practical example and guide discussion onto the question of future challenges and opportunities.
\end{abstract}

Keywords: Anodes, lead acid batteries,

\section{INTRODUCTION}

There are many battery chemistries, both primary and secondary, all of which require robust, efficient electrodes. Battery electrodes can be broadly separated into two components: (1) the active material and (2) an electrically conductive current collector. Nomenclature of battery electrodes and reactions can often be confusing. Traditionally in battery design, anode refers to the negative electrode and cathode refers to the positive electrode. Looking at the electrochemical reactions, however, it is clear that this is only correct for the discharge reactions. While acceptable for primary batteries, this is less satisfactory for secondary batteries. Figure 1 provides a simplified cell diagram for a battery during discharge (supplying a load) and charge (connected to a power supply). Oxidation is an anodic process while reduction is a cathodic process. During discharge, oxidation occurs at the negative electrode with reduction taking place at the positive electrode. During charge, these electrochemical processes are reversed: reduction taking place at the negative electrode and oxidation at the positive electrode. It is therefore more helpful to discuss battery operation in terms of positive and negative electrodes (and their reactions). This paper will therefore primarily discuss the electrode materials associated with the negative electrode reactions. 

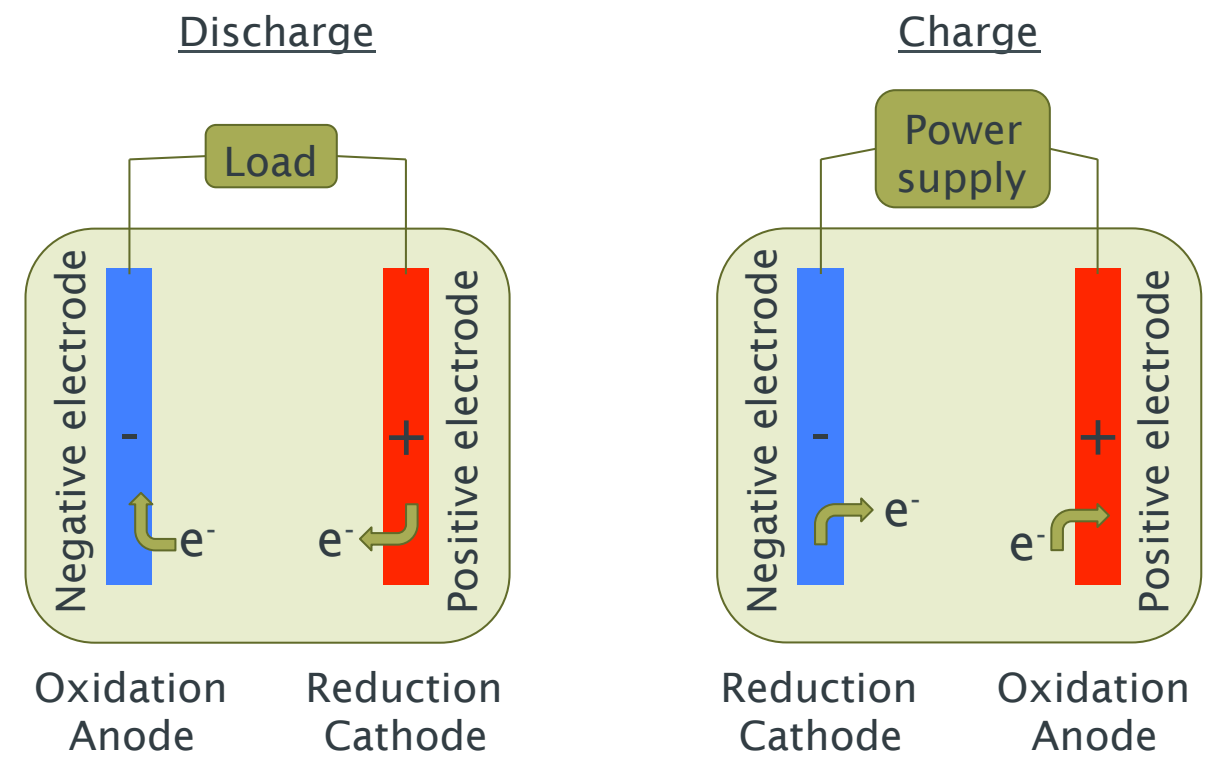

FIGURE 1. Battery and electrode nomenclature convention

\section{BATTERY CHEMISTRIES}

When developing batteries, there are typically a number of universal requirements that need to be balanced:

- Economic and practical

- Low cost, easy to process materials

- Easy to manufacture electrode assemblies

- Widely available; safe and non-toxic materials

- High cell voltage

- Large difference between formal potentials of positive and negative electrode reactions

- Low overpotentials at both electrodes

- High solution/electrolyte conductivity

- High cell current

- High current density and electrode area - balance anode and cathode kinetics

- High energy efficiency

- Low overpotentials and low ohmic drops

$\circ$ High charge and voltage efficiency

It is clear that many of these parameters will influence the choices for active material and current collector both at the negative and positive electrodes. In particular, for the negative electrode, there are a relatively small number of redox couples that dominate in commercial batteries. For primary batteries, zinc, manganese cadmium and lithium are predominantly used. Table 1 lists some of the available variants. ${ }^{1-3}$ Both zinc and lithium negative electrode couples have been successfully paired to several positive electrode couples. In the case of zinc, this is due to its 
relatively high energy density (low atomic weight and 2 electrons per molecule available from the $\mathrm{Zn} / \mathrm{Zn}^{2+}$ change in oxidation state) but also because the electrode potential of the $\mathrm{Zn} / \mathrm{Zn}^{2+}$ couple is towards the potential limit of the operational window for aqueous electrolytes (important for high cell voltage and power density). Lithium is widely utilized for the potentially high energy and power densities achievable with non-aqueous or polymer electrolytes.

TABLE 1. Selected primary battery chemistries ${ }^{1-3}$

\begin{tabular}{lcc}
\hline Negative active material & Positive active material & Cell Voltage \\
\hline $\mathrm{Cd}$ & $\mathrm{HgO}$ & 0.9 \\
$\mathrm{Li}$ & $\mathrm{SOCl}_{2}$ & 3.6 \\
$\mathrm{Li}$ & $\mathrm{SO}_{2}$ & 3.0 \\
$\mathrm{Li}$ & $\mathrm{MnO}_{2}$ & 3.0 \\
$\mathrm{Fi}$ & $\mathrm{FeS}_{2}$ & 1.5 \\
$\mathrm{Ci}$ & $\mathrm{CF}_{\mathbf{x}}$ & 3.0 \\
$\mathrm{Li}$ & $\mathrm{LiI}_{2}$ & 2.8 \\
$\mathrm{Mn}$ & $\mathrm{MnO}_{2}$ & 1.7 \\
$\mathrm{Zn}$ & $\mathrm{HgO}$ & 1.5 \\
$\mathrm{Zn}$ & $\mathrm{Ag}_{2} \mathrm{O}$ & 1.4 \\
$\mathrm{Zn}$ & $\mathrm{O}_{2} / \mathrm{air}$ & 1.6 \\
$\mathrm{Zn}$ & & 1.5 \\
\hline
\end{tabular}

For secondary batteries, choosing electrode couples that are readily reversible, with low overpotentials is paramount. This results in a wider range of chemistries being utilized. Table 2 presents some common secondary battery chemistries. ${ }^{1-3}$ Although a wider range of materials are utilized for the negative electrode active material, lithium and zinc are again represented paired to multiple positive electrode couples.

TABLE 2. Selected secondary battery chemistries ${ }^{1-3}$

\begin{tabular}{ccc}
\hline Negative active material & Positive active material & Cell Voltage \\
\hline $\mathrm{Cd}$ & $\mathrm{AgO}$ & 1.1 \\
$\mathrm{Fe}$ & $\mathrm{Ni}$ oxide & 1.2 \\
$\mathrm{H}_{2}$ & $\mathrm{Ni}$ oxide & 1.2 \\
$\mathrm{Li}_{\mathrm{x}} \mathrm{C}_{6}$ & $\mathrm{Li}_{(1-\mathrm{x})} \mathrm{CoO}_{2}$ & 3.8 \\
$\mathrm{Li}$ & $\mathrm{MnO}_{2}$ & 3.0 \\
$\mathrm{Li}$ & $\mathrm{FeS}_{2}$ & 1.7 \\
$\mathrm{MH}$ & $\mathrm{Ni}$ oxide & 1.2 \\
$\mathrm{Na}$ & $\mathrm{S}$ & 2.0 \\
$\mathrm{Na}$ & $\mathrm{NiCl}_{2}$ & 2.6 \\
$\mathrm{~Pb}$ & $\mathrm{PbO}_{2}$ & 2.0 \\
$\mathrm{Zn}$ & $\mathrm{Ni}$ oxide $^{\mathrm{Zn}}$ & 1.6 \\
$\mathrm{Zn}$ & $\mathrm{AgO}^{\mathrm{BnO}}$ & 1.5 \\
& $\mathrm{Br}_{2}$ & 1.6 \\
\hline
\end{tabular}

The specific energy density for the more common chemistries of lithium-ion, nickel-metal hydride, nickel-cadmium and lead-acid is compared in Figure 2. The figure presents values achieved for commercial cells, the theoretical limit for practical batteries and the theoretical limit for the active material. ${ }^{3}$ The difference between the latter two values represents losses associated with cell packaging, current collectors and terminals. The scale is logarithmic and it is obvious that Li-based systems offer 
the highest energy density of all the batteries. It is worth noting, however, that significant increases in energy density are still possible with the other chemistries.

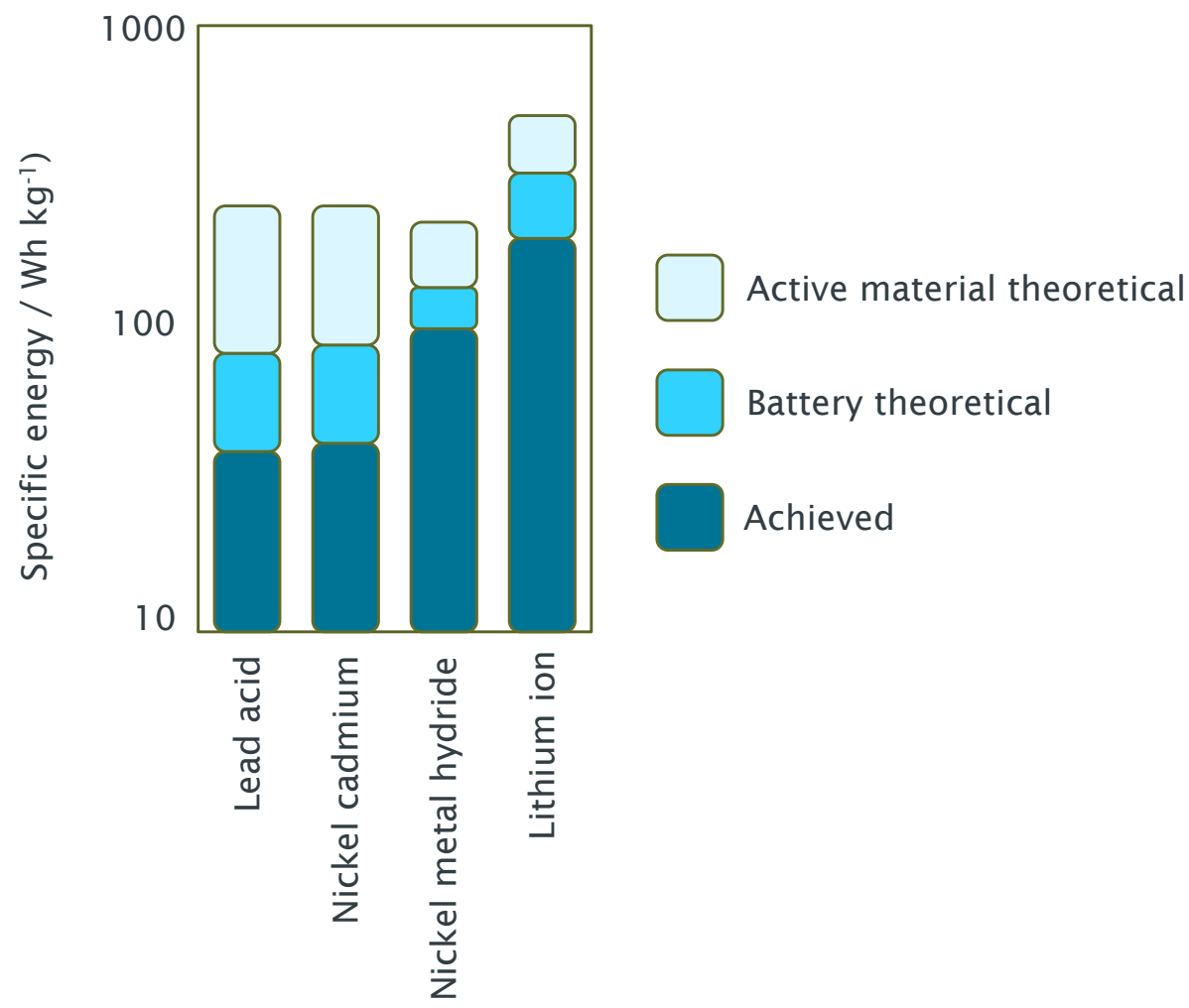

FIGURE 2: Comparison of specific energy values for lead-acid, nickel-cadmium, nickel-metal hydride and lithium-ion battery chemistries. ${ }^{3}$

\section{INCREASING ENERGY DENSITY - CELL CONFIGURATION}

Apart from developing novel battery chemistries, it is possible to design cells with increased energy densities using conventional chemistries. Parameters include reducing cell packaging, increasing active material utilization and developing lightweight current collectors. Battery cells and packs are produced in many configurations, which can have an impact on anode (and cathode) design. Common configurations include:

- Cylindrical

○ Coiled, concentric electrodes

○ Bobbin

- Prismatic

- Planer/folded parallel electrodes

- Pouch

- Foil laminated

- Planer/folded parallel electrodes

- Button 
With the exception of the button cell, each of these configurations utilizes the same method for making electrical contact: a tab at one end of the electrode. Even with highly electrically conductive materials, making electrical connection in this way can result in non-uniform current distribution across the electrode surface. This in turn results in non-uniform active material utilization. Figure 3 presents a stylized schematic of an electrode with a tabbed electrical contact in one corner. Current density is localized in proximity to the tab, decreasing with distance towards the opposite corner. There have also been dual-tab batteries reported in the literature, but these have not reached the market. For example, the Hawker Dual-tab HEV battery has tabs on both ends of the spiral-wound cells in order to sustain the high currents in HEV operation. ${ }^{4}$ It was used in an demonstration HEV for test-track runs.

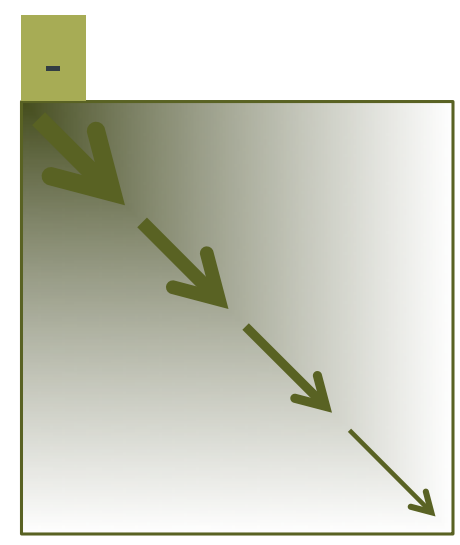

FIGURE 3: Stylized representation of current distribution across an electrode with a tabbed electrical contact in one corner.

A less common battery configuration incorporates bipolar electrodes. In this configuration, individual cells are stacked in series. Between the positive and negative end plates, bipolar electrodes separate the series of individual cells. For each bipolar electrode, one face forms the negative electrode in one cell and the other face forms the positive electrode in the adjacent cell, separates each cell. Figure 4 presents a comparison of the current density distribution for a 3-cell conventional battery pack and a 3-cell bipolar stack. ${ }^{5}$ The magnitude of the arrows qualitatively indicates the current density distribution for each cell. With a bipolar configuration you achieve more uniform current density distribution over the face of the electrodes. This provides more uniform utilization of the active material and improved percentage conversion.

Whether bipolar or monopolar, the electrodes must be electrically conductive and chemically inert (corrosion resistant with high overpotentials for parasitic reactions) within the operational environment. A further consideration is cost. To discuss electrode design in further detail the lead-acid system will be used as a case study. 

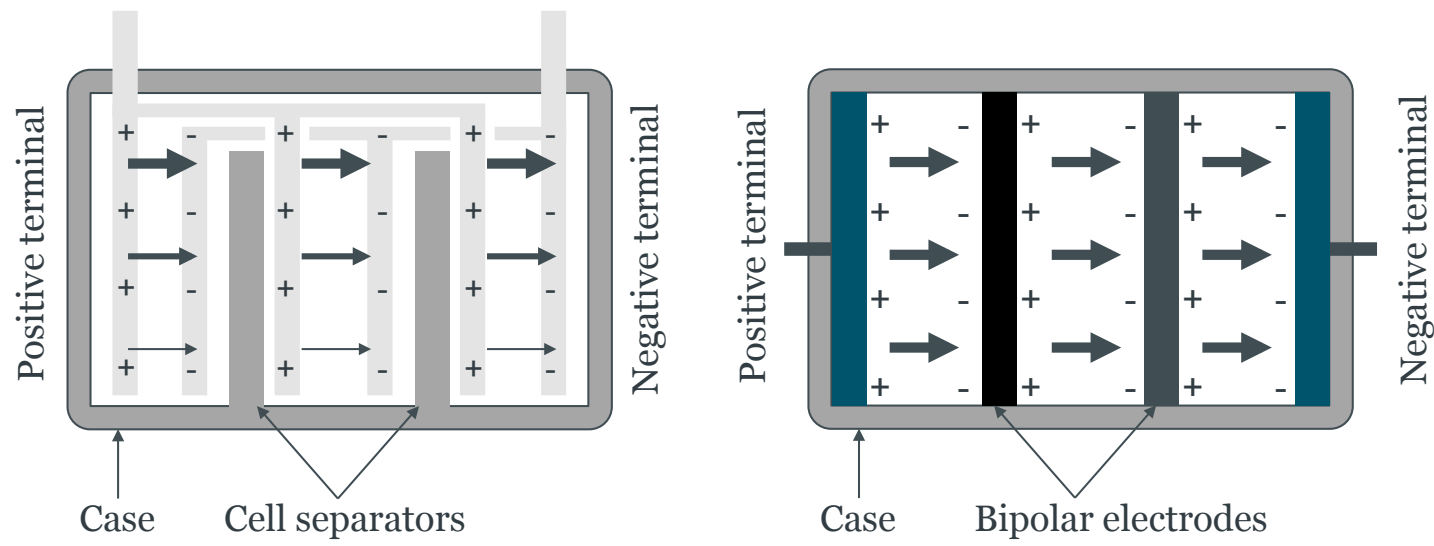

FIGURE 4: Diagram showing current density distribution for a 3-cell conventional battery pack (left) and a 3-cell bipolar stack (right). ${ }^{5}$

\section{CASE STUDY: THE LEAD ACID BATTERY}

Lead-acid batteries are a well-known technology with long development history, however, improvements are still regularly being made to cycle life and reliability. Common variants include small single cells, flooded, gel and AGM (absorbed glass matt) with applications ranging from portable electronics to electric vehicles and large UPS systems. Over the past ten years focus has been put onto increasing the energy and power density of lead-acid cells, particularly for hybrid electric vehicle (HEV) use. With modest improvements in energy density, their low cost and established recycling process would make them attractive for this application.

It is possible to increase energy and power density by increasing active mass utilization, incorporating novel current collector designs, using additives in the negative active mass (NAM), reducing the weight of non-active components (e.g. current collector and cell casing) and using novel designs, such as bipolar configurations or hybrid chemistries. ${ }^{6}$

Traditionally, lead-acid cells have used lead and lead-alloy current collectors. The negative (and positive) active masses are pasted onto the current collector during battery manufacturing. Because the electrode reactions involve conversion of the active material between lead and lead sulfate (negative electrode) and lead dioxide and lead sulfate (positive electrode), the lead-based current collector provides an electrically conductive support but more importantly a surface onto which the active material can chemically bond to. Lead and lead alloys, however, are dense materials, which add bulk to the battery. Replacing this component with less dense materials would increase energy density. Bearing in mind the requirement to be chemically stable in sulfuric acid, electrically conductive and have low overpotentials for parasitic reactions in the potential range associated with the $\mathrm{Pb} / \mathrm{Pb}^{2+}$ and $\mathrm{Pb}^{2+} / \mathrm{Pb}^{4+}$ redox couples, materials from the following groups can be used: 
- Carbon

- Foam, cloth, composites, coated

- Conductive polymers

- Conductive ceramics

- Coated metals

Titanium, aluminium and copper have been investigated as possible metallic current collectors. All three require coating with a chemically inert material to prevent corrosion or surface passivation. Barium metaplumbate, Doped and undoped $\mathrm{SnO}_{2}$, polyaniline and Magneli phase titanium sub-oxides have all been used as conductive coatings to protect metallic substrates. In addition, thin layers of lead can be used to protect substrates and provide a suitable surface for keying in of the NAM and PAM. In addition to being used as a coating, Magneli phase materials, under the trade name Ebonex, have also been used as bulk current collectors (usually with the addition of a thin layer of metallic lead for paste adhesion. ${ }^{7-16}$

Most research effort aimed at replacing lead-alloy current collectors has focused on carbon. Carbons with a wide range of properties and morphologies have been investigated, some of which are shown in figure 5.

The different carbons exhibit a variation in their electrochemical response in the lead acid system. Differences arise from the feedstocks used to prepare the carbon, to processing techniques and carbon type (vitreous/glassy, graphitic, amorphous). For example, the onset of hydrogen evolution at the negative electrode can differ by around $350 \mathrm{mV}$ between samples: ${ }^{17}$

- Natural graphite showing hydrogen onset at circa $-0.65 \mathrm{~V}$ vs. SCE.

- Pitch-based carbon inhibiting hydrogen evolution until circa-1.0 V vs. SCE.

Pitch-based carbon foam shows the lowest gas evolution rates. It also has the lowest capacitance charging. Carbon has much higher impedance than lead alloys so is more suitable for bipolar electrode configurations compared to tabbed electrodes. 


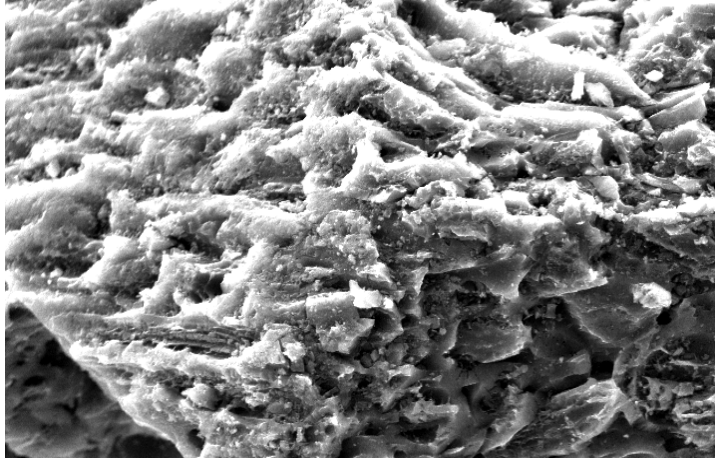

Activated carbon
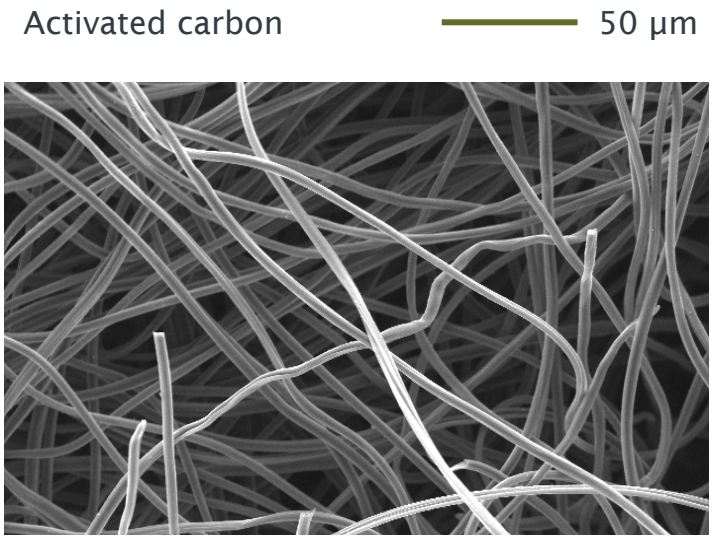

Felt

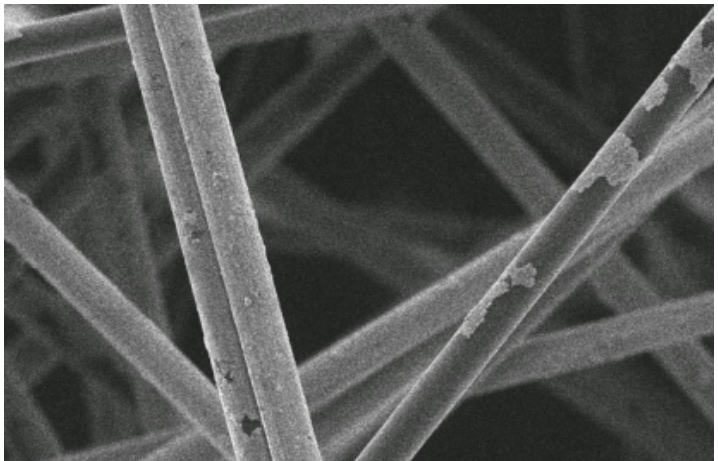

Mesh

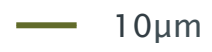

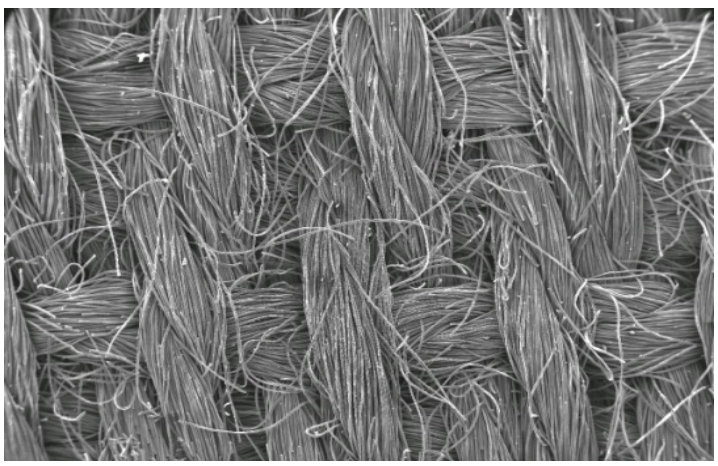

Woven cloth

$1 \mathrm{~mm}$

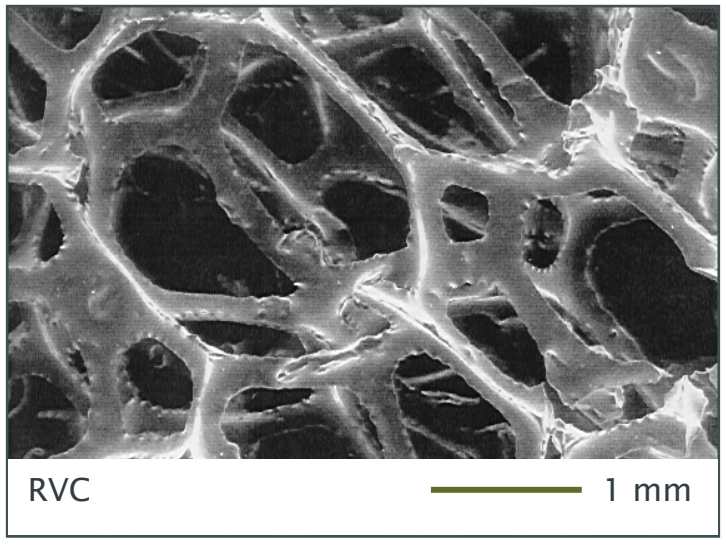

FIGURE 5: SEM images of carbon materials

\section{SUMMARY}

Many challenges remain for anode development. All battery technologies require electrodes that are economic and practical, provide a high cell voltage, are able to sustain a high cell current and have good energy efficiency. Electrodes are also required to be incorporated into many configurations, including, cylindrical, button, prismatic and bipolar. Carbon is an important electrode material that combines a good balance of chemical stability, electrical conductivity and low density. Improved coatings for carbon and other, less chemically stable, lightweight substrate materials 
need further development and testing in practical devices. Such lightweight current collectors, however, have the potential to increase significantly the energy density of conventional battery systems such as lead-acid and nickel-metal hydride as well as being incorporated into more novel, developing battery chemistries.

\section{REFERENCES}

1. C. Daniel and J. O. Besenhard, Handbook of Battery Materials, Weinheim: Wiley-VCH, 2012.

2. R-S. Liu, L. Zhang, X. Sun, H. Liu and J. Zhang, Electrochemical Technologies for Energy Storage and Conversion, Weinheim: Wiley-VCH, 2012.

3. T. B. Reddy, Linden's Handbook of Batteries, New York: McGraw Hill, 2011.

4. A. Cooper, J. Power. Sourc. 133. 116-125 (2004).

5. R. G. A. Wills and F. C. Walsh, Electrochim. Acta, 55, (22), 6342-6351 (2010).

6. D. A. J. Rand, J. Power. Sourc, 64. 157-174 (1997).

7. H. Karami, M. Shamsipur, S. Ghasemi, and M. Mousavi. Lead acid bipolar battery assembled with primary chemically formed positive pasted electrode. Journal of Power Sources, 164:896 904, February 2007.

8. M. Soria, J. Fullea, F. Saez, and F. Trinidad. J. Power. Sourc, 78. 220-230 (1099).

9. M. Raghavan and D. C. Trivedi. J. Synth. Mat. 119 285-286 (2001).

10. I. Paleska, R. Pruszkowska-Drachal, J. Kotowski, Z. Rogulski, J. D. Milewski, and A. Czerwinski, J. Power. Sourc, 129 326-329 (2004).

11. W. Utomo and S. W. Donne. Electrochim. Acta, 51 3338-3345 (2006).

12.I Kurisawa. J. Power. Sourc, 95 125-129 (2001).

13. N. Yu and L. Gao. Electrochem. Comm. 11 220-222 (2009).

14. A. Czerwinski, S. Obrebowski, and Z. Rogulski. J. Power. Sourc, 198 378-382 (2012).

15. A. Kirchev, N. Kircheva, and M. Perrin. J. Power. Sourc, 198 8773-8788 (2011).

16. M. Gardon, S. Dosta, J.M. Guilemany, M. Kourasi, B. Mellor, R. Wills, J. Power. Sourc, 238, 430$434(2013)$.

17. Y. Chen, B. Z. Chen, L. W. Ma, and Y. Yuan. J. Appl. Electrochem. 38 1409-1413 (2008). 